\title{
Does patient health literacy impact adherence to adjuvant endocrine therapy in breast cancer patients?
}

This article was published in the following Dove Medical Press journal: Patient Preference and Adherence

\author{
Jessica Keim-Malpass' \\ Aubrey Doede' \\ Shayna L Showalter ${ }^{2}$ \\ 'Department of Acute and Specialty \\ Care, University of Virginia School \\ of Nursing, Charlottesville, VA \\ 22908, USA; ${ }^{2}$ Department of \\ Surgery, University of Virginia \\ School of Medicine, Charlottesville, \\ VA 22908, USA
}

Purpose: Functional health literacy is critical for patients' functional understanding and management of disease including adherence to medications and treatment recommendations. The purpose of this study was to determine if there is a relationship between self-reported health literacy and 1) decision to take adjuvant endocrine therapy and 2) adherence to adjuvant endocrine therapy at 2 years among women with breast cancer.

Methods: We initiated a prospective health literacy assessment to determine the relationship between health literacy and breast health outcomes. Among our overall cohort, we determined women who had estrogen receptor positive $(\mathrm{ER}+)$ disease and were recommended to take adjuvant endocrine therapy, those who initiated treatment, and those adherent at 2 years following diagnosis. Descriptive statistics and logistic regression were calculated to determine the relationship between health literacy and both initiation and adherence.

Results: Among the 340 patients in the sample who were recommended to take adjuvant endocrine therapy, $296(87.1 \%)$ initiated the therapy. Two-year follow-up data are available in 136 patients with ER+ tumors. Among the patients with 2-year longitudinal data available, 108 (79.4\%) were adherent and still taking the endocrine therapy at 2 years following diagnosis. In univariate logistic regression analysis, there was no statistical significance between health literacy and initiation of adjuvant endocrine therapy or adherence to adjuvant endocrine therapy at 2 years.

Conclusion: Despite the underpinnings regarding health literacy and medication adherence supporting our hypothesis, we did not find an association between health literacy and the decision to initiate therapy or continued adherence at 2 years following diagnosis. Further study is needed to determine the nuances in adherence to adjuvant endocrine therapy for women with breast cancer.

Keywords: health literacy, adjuvant endocrine therapy, breast cancer, adherence

\section{Introduction}

Health literacy has been defined as "the degree to which individuals have the capacity to obtain, process, and understand basic health information and services needed to make appropriate health decisions" and has been recognized as a critical component of highquality health care. ${ }^{1}$ It is estimated that up to $26 \%$ of the US adult population has low health literacy, which likely impairs both written and verbal health communications. ${ }^{2}$ Within the scope of clinical and health service research, health literacy is often applied to a set of skills that are required to function within the health care setting and selfmanage the disease. ${ }^{3}$ Although the skills associated with health literacy are primarily centered on general reading ability, health literacy also encompasses patients' ability
Correspondence: Jessica Keim-Malpass University of Virginia School of Nursing PO Box 800782, Charlottesville, VA 22908, USA

$\mathrm{Tel}+|434243396|$

Fax + I 4349242787

Email jlk2t@virginia.edu 
to thrive within the health system. ${ }^{4}$ Functional health literacy also supports broader health constructs and a patient's functional understanding and management of disease including adherence to medications and treatment recommendations.

Breast cancer represents the leading new cancer diagnosis for women in USA. ${ }^{5}$ Following successful treatment of breast cancer, women remain at the risk of breast cancer local and distant recurrence. ${ }^{6}$ Breast cancer patients with estrogen receptor positive $(\mathrm{ER}+)$ disease are often prescribed adjuvant anti-estrogen endocrine therapy for 5-10 years in order to decrease the risk of recurrence. ${ }^{7,8}$ Despite the recommendation, non-adherence to adjuvant endocrine therapy is a common occurrence primarily due to the side effects of the therapy or existing co-morbidities (eg, depression). ${ }^{6,9}$ Arthralgias/myalgias, thromboembolic events, and hot flushes/night sweats have been reported to be the top three side effects that women have reported as reasons for discontinuing endocrine treatment. ${ }^{10}$ There are also women who are counseled to receive adjuvant endocrine therapy due to their clinical status and decide against it because of the side effects, representing non-initiation. ${ }^{9}$

In previous studies, reports of the relationship between health literacy and medication adherence have been mixed with several reports, suggesting that there is a relationship between higher health literacy and higher self-reported levels of medication adherence among those with chronic illnesses that require a daily medication regimen. ${ }^{11-17}$ Health literacy has been associated with proactive health information seeking, which could enhance the understanding of the relationship between adherence to adjuvant endocrine therapy on overall breast cancer survival. ${ }^{18}$ It is not yet known how health literacy can be used to predict important health outcomes related to engagement in shared decision making and adherence with medications such as adjuvant endocrine therapy. The purpose of this study was to determine if there is a relationship between self-reported health literacy and 1) decision to take adjuvant endocrine therapy and 2) adherence to adjuvant endocrine therapy at 2 years among women with breast cancer. Our hypothesis was that lower patient health literacy would be associated with poor adherence to adjuvant endocrine therapy at 2 years.

\section{Methods}

We undertook a prospective observational study. Institutional Review Board approval (number 19508 from the University of Virginia) was obtained to implement the three-question screener and create a health literacy clinical breast database. We have previously reported how the health literacy screener was implemented, integrated within the electronic medical record, and used in routine clinical operations. ${ }^{24}$ Because the health literacy screen was implemented as a quality improvement measure with electronic medical record abstraction, this protocol operated under a waiver of informed consent.

\section{Health literacy measure}

A health literacy screening questionnaire was administered to all new and returning breast cancer patients beginning in June 2015 in an academic breast surgical oncology setting in USA. ${ }^{19,20}$ The health literacy measure included the Set of Brief Screening Questions (SBSQ), a patient-reported three-item health literacy assessment. ${ }^{21-23}$ The health literacy measure was originally developed and validated as a screening measure that could be implemented in a busy clinic environment. ${ }^{21-23}$ Unlike other gold standard assessments such as the Test of Functional Health Literacy in Adults (TOFHLA), the three-question nature of the SBSQ can be administered with less stigma than the more traditional word-based recall and has also been validated in Spanish. ${ }^{21}$ The SBSQ can discriminate English and Spanish speakers with adequate health literacy from those with inadequate and inadequate plus marginal health literacy (concordance index 0.82 and 0.82 , respectively). ${ }^{21}$

The three questions involve a Likert scale response from 1 (extremely) to 5 (not at all) of perceptions related to 1) How confident are you in filling out medical forms?, 2) How often do you have problems learning about your medical condition(s) because of difficulty understanding written information?, and 3) How often do you have someone help you read hospital materials? Scores can range from 3 to 15 with scores 9 and above classified as "limited health literacy" and scores between 7 and 8 as "marginal health literacy". The combination of "limited" and "marginal" health literacy can further be classified as low health literacy. In terms of interpretation, lower scores on the health literacy scale represent higher self-reported health literacy.

We also obtained demographic and clinical variables both from chart review and through the University of Virginia Clinical Data Repository (a claims database). Variables included the following: age at diagnosis, race, insurance type (private insurance, public insurance, and no insurance), cancer type, cancer stage at presentation, hormonal status, and whether or not the patient was recommended to take adjuvant endocrine therapy, whether endocrine therapy was initiated, and whether the patient was adherent at 2 years after diagnosis. Adherence was defined as either yes or no at the 2-year follow-up time point and was not calculated as a percentage of time the person took the drug. This determination 
was made because unlike other daily medications, women who stop taking adjuvant endocrine therapy may try to switch classes, but ultimately stop overall instead of demonstrating days or weeks at a time where they are not adherent, but remain taking the medication overall. ${ }^{10}$ Determination of specifics regarding adjuvant endocrine therapy recommendations and adherence was done through reading medical oncology patient notes and was based on physician ascertainment of adherence, not on self-report or prescription records. In other words, when the women have routine follow-up visits with their medical oncology providers (ie, the prescribers of the adjuvant endocrine therapy), it is normal practice for their providers to document if they are still taking the therapy, side effects experienced, etc in the medical record through the medical oncology clinic note.

\section{Analysis}

Descriptive statistics were calculated to describe health literacy and demographic and clinical characteristics of patients. Univariate logistic regression was used to determine the relationship between health literacy and initiation of adjuvant endocrine therapy and adherence to adjuvant endocrine therapy at 2 years. Both outcomes were assessed among patients who were hormone sensitive and recommended to take adjuvant endocrine therapy.

\section{Results}

A total of 512 participants were included in this analysis. The women with breast cancer were predominantly White and had private insurance with early-stage (stages 0 and 1) cancer diagnoses (Table 1). Among the 512 patients in the overall study cohort, $340(66.4 \%)$ were advised to take adjuvant endocrine therapy due to their hormone sensitivity status of the breast cancer and medical oncology recommendations (Table 1). Among the 340 patients in the sample who were recommended to take adjuvant endocrine therapy, $296(87.1 \%)$ initiated the therapy. Two-year follow up data are available in 136 patients with ER+ tumors. Among the patients with 2-year longitudinal data available, 108 (79.4\%) were adherent and still taking the endocrine therapy at 2 years following diagnosis.

In univariate logistic regression analysis, there was no statistical significance between health literacy and initiation of adjuvant endocrine therapy or adherence to adjuvant endocrine therapy at 2 years. Mean health literacy scores between 1) initiators vs non-initiators of endocrine therapy and 2) those who were adherent at 2 years vs those who were not significantly different (Table 2 ).
Table I Characteristics of patients $(\mathrm{N}=5 \mid 2)$

\begin{tabular}{|c|c|}
\hline Variables & $\begin{array}{l}\text { Mean (SD) or } \\
\text { frequency (\%) }\end{array}$ \\
\hline Age, years & $59.2(12.0)$ \\
\hline $\begin{array}{l}\text { Race } \\
\text { White } \\
\text { Non-White }\end{array}$ & $\begin{array}{l}409(80.0 \%) \\
103(20.0 \%)\end{array}$ \\
\hline $\begin{array}{l}\text { Insurance status } \\
\text { Private insurance } \\
\text { Public insurance (Medicare, Medicaid) } \\
\text { No insurance } \\
\text { Missing }\end{array}$ & $\begin{array}{l}231(45.1 \%) \\
195(38.1 \%) \\
33(6.4 \%) \\
53(10.4 \%)\end{array}$ \\
\hline $\begin{array}{l}\text { Cancer type } \\
\text { Invasive ductal carcinoma } \\
\text { Invasive lobular carcinoma } \\
\text { Ductal carcinoma in situ } \\
\text { Others }\end{array}$ & $\begin{array}{l}322(62.9 \%) \\
46(9.0 \%) \\
134(26.2 \%) \\
10(2.0 \%)\end{array}$ \\
\hline $\begin{array}{c}\text { Stage } \\
0 \\
1 \\
2 \\
3 \\
4\end{array}$ & $\begin{array}{l}124(24.2 \%) \\
208(40.6 \%) \\
130(25.4 \%) \\
39(7.6 \%) \\
11(2.1 \%)\end{array}$ \\
\hline $\begin{array}{l}\text { Health literacy (raw score) } \\
\text { Low health literacy (combined limited } \\
\text { and marginal) } \\
\text { Limited health literacy } \\
\text { Marginal health literacy } \\
\text { Adequate health literacy }\end{array}$ & $\begin{array}{l}5.7(2.5) \\
131(25.6 \%) \\
62(12.1 \%) \\
69(13.5 \%) \\
381(74.4 \%)\end{array}$ \\
\hline $\begin{array}{l}\text { Recommended to take adjuvant endocrine } \\
\text { therapy } \\
\text { Yes } \\
\text { No }\end{array}$ & $\begin{array}{l}340(66.4 \%) \\
172(33.6 \%)\end{array}$ \\
\hline $\begin{array}{l}\text { Endocrine therapy initiated among those who } \\
\text { were recommended to take endocrine therapy } \\
(\mathrm{n}=340) \\
\text { Initiated } \\
\text { Did not initiate }\end{array}$ & $\begin{array}{l}296 \text { (87.1\%) } \\
44 \text { (I2.9\%) }\end{array}$ \\
\hline $\begin{array}{l}\text { Adherence at } 2 \text { years among those who were } \\
\text { recommended to take endocrine therapy } \\
\text { ( } \mathrm{n}=136) \\
\text { Adherent } \\
\text { Non-adherent }\end{array}$ & $\begin{array}{l}108(79.4 \%) \\
28(20.6 \%)\end{array}$ \\
\hline
\end{tabular}

Table 2 Mean health literacy scores by group (lower health literacy scores represent higher levels of health literacy)

\begin{tabular}{|l|l|l|}
\hline & $\begin{array}{l}\text { Health literacy } \\
\text { mean score (SD) }\end{array}$ & P-value \\
\hline $\begin{array}{l}\text { Endocrine therapy } \\
\text { Initiated } \\
\text { Did not initiate }\end{array}$ & $5.05(2.35)$ & 0.426 \\
\hline $\begin{array}{l}\text { Adherence at 2 years } \\
\text { Adherent } \\
\text { Non-adherent }\end{array}$ & $\begin{array}{l}4.25(2.50) \\
5.18(2.09)\end{array}$ & 0.645 \\
\hline
\end{tabular}




\section{Discussion}

To our knowledge, this report offers the first assessment of the relationship between patient literacy to initiation of adjuvant endocrine therapy and long-term adherence to therapy for breast cancer patients with ER+ disease. Our finding of a $20.6 \%$ non-adherence rate at 2 years is in line with other sample estimates ranging from $19.9 \%$ to $23 \%$ non-adherence at 5 years. ${ }^{6,9}$ Despite the underpinnings regarding health literacy and medication adherence supporting our hypothesis, we did not find an association between health literacy and the decision to initiate therapy or continued adherence at 2 years following diagnosis. ${ }^{14}$

The relationship between health literacy and adherence to endocrine therapy in breast cancer patients has important clinical implications and therefore warrants further study with larger and more diverse samples. Although we hypothesized that women with low health literacy would have a corresponding lower rate of adherence to endocrine therapy, we did not find this to be the case. Women with high health literacy are likely able to assess relevant health information and make informed choices regarding their own personal risk benefit, which may make them more comfortable with therapy discontinuation. In other words, if a woman with high health literacy is suffering from side effects related to endocrine therapy that is impacting her quality of life, she may be able to appraise the recommendations at a different more personal level (beyond general recommendations) and understand that she is personally impacting her 5-year survival by a certain percentage if she stops taking the endocrine therapy. This may lead her to feel comfortable with taking on that risk of cancer recurrence knowing that her quality of life may increase again after discontinuing the endocrine therapy. Additionally, adherence in ER+ breast cancer may be different than other chronic disease medications. Because side effects are reported as the most common reasons for non-adherence, women who are non-adherent discontinue it outright instead of missing days or weeks at a time..$^{10,25}$ Understanding the differences in perceptions of risk and variation in shared decision making regarding adherence for both high and low health literacy patients may offer a balanced approach for future study. Additionally, in larger samples, it is critical to understand the role of other sociodemographic factors in moderating health literacy and we were not able to fully explore this due to a fairly homogenous sample size.

\section{Limitations}

This study represents a novel and needed assessment of the potential relationship between health literacy and the decision to take and adhere to adjuvant endocrine therapy in breast cancer patients with ER+ breast cancer. Despite this, several limitations must be discussed. The three-question health literacy screener that we chose and introduced to the clinic workflow in both English and Spanish was a selfassessment rather than the gold-standard approach that relies on word recognition or numeracy tests. The reason we chose the self-reported brief SBSQ was to limit potential stigma and ensure that it was able to be completed in a routine clinical practice environment. ${ }^{19}$ However, we are confident with the assessment, given the estimated clinic point prevalence of $25.6 \%$ representing that low health literacy is in line with other national estimates. ${ }^{2}$ Additionally, the way we assessed for adherence was based on physician report in the clinic note and not self-report or pharmacy claims records, which could lead to bias in overestimating adherence at 2 years. Because of loss to follow-up and the 2-year time period ascertained, we might only be seeing a snapshot and not fully understanding the entire 5 or 10 -year adjuvant endocrine therapy trajectory. Finally, the participants were recruited from a single-center academic breast surgical clinic and therefore the generalizability may be limited to other academic centers.

\section{Acknowledgment}

This work was supported by an internal University of Virginia Women's Four Miler Breast Care grant.

\section{Disclosure}

The authors report no conflicts of interest in this work.

\section{References}

1. IOM. Health Literacy: A Prescription to End Confusion. NielsenBohlman L, Panzer AM, Kindig DA, editors. Washington, DC: The National Academies Press; 2004.

2. Paasche-Orlow MK, Parker RM, Gazmararian JA, Nielsen-Bohlman LT, Rudd RR. The prevalence of limited health literacy. J Gen Intern Med. 2005;20(2):175-184.

3. Dewalt DA, Hink A. Health literacy and child health outcomes: a systematic review of the literature. Pediatrics. 2009;124(Suppl):S265-S274.

4. Dewalt DA, Boone RS, Pignone MP. Literacy and its relationship with self-efficacy, trust, and participation in medical decision making. Am J Health Behav. 2007;31(Suppl 1):S27-S35.

5. Siegel R, Desantis C, Virgo K, et al. Cancer treatment and survivorship statistics, 2012. CA Cancer J Clin. 2012;62(4):220-241.

6. Sedjo RL, Devine S. Predictors of non-adherence to aromatase inhibitors among commercially insured women with breast cancer. Breast Cancer Res Treat. 2011;125(1):191-200.

7. Kwon JS, Pansegrau G, Nourmoussavi M, Hammond GL, Carey MS. Costs and benefits of extended endocrine strategies for premenopausal breast cancer. J Natl Compr Canc Netw. 2017;15(8):1015-1021.

8. Hershman DL, Tsui J, Meyer J, et al. The change from brand-name to generic aromatase inhibitors and hormone therapy adherence for earlystage breast cancer. J Natl Cancer Inst. 2014;106(11):1-9. 
9. Cahir C, Barron TI, Sharp L, Bennett K. Can demographic, clinical and treatment-related factors available at hormonal therapy initiation predict non-persistence in women with stage I-III breast cancer? Cancer Causes Control. 2017;28(3):215-225.

10. Chirgwin JH, Giobbie-Hurder A, Coates AS, et al. Treatment adherence and its impact on disease-free survival in the breast international group 1-98 trial of tamoxifen and letrozole, alone and in sequence. $J$ Clin Oncol. 2016;34(21):2452-2459.

11. Dharmapuri S, Best D, Kind T, Silber TJ, Simpson P, D'Angelo L. Health literacy and medication adherence in adolescents. J Pediatr. 2015;166(2): 378-382.

12. Berkman ND, Sheridan SL, Donahue KE, et al. Health literacy interventions and outcomes: an updated systematic review. Evid Rep Technol Assess (Full Rep). 2011;(199):1-941.

13. Keim-Malpass J, Letzkus LC, Kennedy C. Parent/caregiver health literacy among children with special health care needs: a systematic review of the literature. BMC Pediatr. 2015;15(1):92.

14. Zhang NJ, Terry A, McHorney CA. Impact of health literacy on medication adherence: a systematic review and meta-analysis. Ann Pharmacother. 2014;48(6):741-751.

15. Janisse HC, Naar-King S, Ellis D. Brief report: parent's health literacy among high-risk adolescents with insulin dependent diabetes. J Pediatr Psychol. 2010;35(4):436-440.

16. Aboumatar HJ, Carson KA, Beach MC, Roter DL, Cooper LA. The impact of health literacy on desire for participation in healthcare, medical visit communication, and patient reported outcomes among patients with hypertension. J Gen Intern Med. 2013;28(11):1469-1476.
17. Bauer AM, Schillinger D, Parker MM, et al. Health literacy and antidepressant medication adherence among adults with diabetes: the diabetes study of Northern California (DISTANCE). J Gen Intern Med. 2013;28(9):1181-1187.

18. Neter E, Brainin E, Hefer E. eHealth literacy: extending the digital divide to the realm of health information. J Med Internet Res. 2012; 14(1):e19.

19. Keim-Malpass J, Doede A, Kennedy C, Showalter SL. Health literacy assessment: feasibility in a breast surgical oncology clinic. Clin J Oncol Nurs. 2017;21(3):384-386.

20. Keim-Malpass J, Doede A, Camacho F, Kennedy C, Showalter SL. Impact of patient health literacy on surgical treatment of breast cancer. Breast J. 2018;24(4):633-636.

21. Sarkar U, Schillinger D, López A, Sudore R. Validation of self-reported health literacy questions among diverse English and Spanish-speaking populations. J Gen Intern Med. 2011;26(3):265-271.

22. Chew LD, Bradley KA, Boyko EJ. Brief questions to identify patients with inadequate health literacy. Fam Med. 2004;36(8):588-594.

23. Chew LD, Griffin JM, Partin MR, et al. Validation of screening questions for limited health literacy in a large VA outpatient population. J Gen Intern Med. 2008;23(5):561-566.

24. Keim-Malpass J, Doede A, Kennedy C, Showalter SL, Showalter shayna. health literacy assessment: feasibility in a breast surgical oncology clinic. Clin J Oncol Nurs. 2017;21(3):384-386.

25. Doggrell SA. Adherence to oral endocrine treatments in women with breast cancer: can it be improved? Breast Cancer Res Treat. 2011;129(2) 299-308.
Patient Preference and Adherence

\section{Publish your work in this journal}

Patient Preference and Adherence is an international, peer-reviewed, open access journal that focuses on the growing importance of patient preference and adherence throughout the therapeutic continuum. Patient satisfaction, acceptability, quality of life, compliance, persistence and their role in developing new therapeutic modalities and compounds to optimize

\section{Dovepress}

clinical outcomes for existing disease states are major areas of interest for the journal. This journal has been accepted for indexing on PubMed Central. The manuscript management system is completely online and includes a very quick and fair peer-review system, which is all easy to use. Visit http://www. dovepress.com/testimonials.php to read real quotes from published authors. 